\title{
Benign Lung Neoplasm
}

National Cancer Institute

\section{Source}

National Cancer Institute. Benign Lung Neoplasm. NCI Thesaurus. Code C4454.

A non-metastasizing neoplasm that arises from the lung parenchyma or the bronchi.

Representative examples include lung adenoma, lung hamartoma, and endobronchial lipoma. 